\title{
Electron microscopy of pulmonary vasculature after application of fulvine
}

\author{
C. A. WA GEN VOORT, K. P. D I N G E M A N S, \\ and G. G. LOT GER ING \\ Department of Pathological Anatomy, Wilhelmina Gasthuis, \\ University of Amsterdam, The Netherlands
}

\begin{abstract}
Wagenvoort, C. A., Dingemans, K. P., and Lotgering, G. G. (1974). Thorax, 29, 511-521. Electron microscopy of pulmonary vasculature after application of fulvine. This is an electron microscopic study of the effect of fulvine on the pulmonary arteries and veins of the rat. Marked constriction of the arteries was evident from excessive crenation of the internal elastic membrane, resulting in squeezing of nuclei of both smooth muscle cells and endothelial cells between the folds on either side of this lamina.

Four weeks after fulvine administration fibrin deposits were found in the arterial media followed by necrosis of muscle cells. In the adventitia there was a new development of smooth muscle fibres, probably derived from fibroblasts.

In pulmonary veins and venules there was also constriction and hyperplasia of smooth muscle. The muscle cells showed pronounced cytoplasmic excrescences protruding into the endothelial layer. This probably reflects constriction of the muscle cells. As in the arteries, fibrin deposits and necrosis of muscle cells were observed from the fourth week onward.
\end{abstract}

Fulvine, when applied to rats as a single oral or intraperitoneal dose, produces severe changes in both pulmonary arteries and pulmonary veins. The histology of these pulmonary vascular changes has been described in the preceding paper (Wagenvoort, Wagenvoort, and Dijk, 1974). In the muscular pulmonary arteries and arterioles, thickening of the media due to vasoconstriction and medial hypertrophy and fibrinoid necrosis with arteritis was observed. In the pulmonary veins and venules there was some increase in collagen and proliferation of the intimal muscle fibres and endothelial cells.

Electron microscopical investigation of these vascular lesions was the purpose of the present study and therefore, with regard to the ultrastructural changes, we have concentrated upon the pulmonary arteries and veins.

\section{MATERIAL AND METHODS}

From each rat a piece of lung tissue was taken and cut into small cubes of approximately $1 \mathrm{~mm}^{3}$. These were fixed partly in glutaraldehyde $(2 \%$ in cacodylate buffer) followed by osmic acid (1\%) and partly in osmic acid alone. After being embedded in Epon, sections were cut at $1 \mu \mathrm{m}$ and stained with toluidine blue. These were used for light microscopical orientation and for selection of pulmonary arteries and veins suitable for ultrastructural investigation. Subsequently the blocks were trimmed and ultra-thin sections were cut with an LKB ultramicrotome at approximately 600 to $700 \AA$. These sections were stained with uranyl magnesium acetate and lead citrate and examined with a Philips EM 300 electron microscope.

In five instances, after the ultra-thin sections had been obtained, the remainder of the blocks were cut serially at $1 \mu \mathrm{m}$ and in the uninterrupted series, stained with toluidine blue, the small pulmonary vessels were traced with the light microscope. When it was difficult to decide whether a vessel was an arteriole or a venule, its nature could thus be established by tracing it to a larger and recognizable vessel.

The ultrastructure of the pulmonary vessels from 15 test rats was compared with that of six normal control rats. Of these test rats, two had survived fulvine administration for one week, two for two, two for three, seven for four, and two for six weeks.

\section{RESULTS}

The normal muscular pulmonary arteries and arterioles, as revealed in the six control rats, are characterized by external and internal elastic 
laminae on each side of the muscular media. The internal elastic lamina is crenated due to collapse of the vessels. The smooth muscle cells of the media are separated by small numbers of collagen fibres. Their nuclei have an irregular outline. The cytoplasm of the smooth muscle cells has a fibrillar structure from its content of myofibrils. Moreover there are scattered fusiform densities and paranuclear clusters of organelles. Extensions of the cytoplasm, lined by the muscle cell membrane, fill the spaces formed by the coiling of the internal elastic lamina.

The endothelial cells generally protrude into the lumen. They rest on a basement membrane, closely overlying the internal elastic lamina. Their nuclei usually have a smooth contour on the luminal side but are irregular at their bases. Their cytoplasm possesses abundant pinocytotic vesicles and, particularly in the cell body, some mitochondria, many electron-dense lysosome-like bodies, and scanty endoplasmic reticulum.

In the fulvine-treated animals, increased contraction of the muscular media became apparent from the coiled appearance of the muscular nuclei and from excessive crenation of the internal elastic lamina. Nuclei of smooth muscle cells sometimes were partly squeezed between the folds of this lamina (Fig. 1) and the same happened to endothelial nuclei on the other side (Fig. 2). This increased contraction was observed occasionally one week after fulvine application but most without exception after two or more weeks. Squeezing of the nuclei was absent in control rats.

Cytoplasmic organelles were never abundant in the smooth muscle cells, although there was a varying, sometimes marked, increase from the second week onward. The muscle cells sometimes formed small blebs, protruding into both the internal and external elastic laminae.

Hyperplasia of the muscle cells was evident from occasional mitotic activity (Fig. 2). In addition, there was the development of smooth muscle cells outside the external elastic lamina (Fig. 3) in a circular arrangement. It is very likely that these muscle cells are derived from adventitial fibroblasts since images were observed which suggested transitions between the two types of cell.

Four weeks after administration of the drug fibrin was found in the media of the pulmonary arteries. In the early stages this was seen as dense fibrillar streaks and irregular masses in the intercellular spaces. In some instances it extended into the cytoplasm of muscle cells. This material was fibrillar with a periodicity of approximately $180 \AA$
(Fig. 3). At a later stage the amount of fibrin increased so much that in some arteries the media $\frac{\overline{0}}{\bar{D}}$ was almost completely replaced by dense deposits of fibrin. The fibrin even extended into the adven- $\varrho$ titia, at least in those arteries in which smooth os muscle cells had developed in this layer (Fig. 3). $\overrightarrow{0}$

While initially the muscle fibres apparently re- $\overrightarrow{-}$ tained an intact structure, gradually with increasing amounts of deposits the muscle cells $\nRightarrow$ disintegrated. They lost their fibrillar structure and showed excessive dilatation of endoplasmic 0 reticulum and karyolysis. Necrotic cells with only ir remnants of the original cytoplasm could even be $\stackrel{G}{\vec{T}}$ observed lying loose in the lumen of the vessel. $\overrightarrow{0}$ In all these instances the internal elastic lamina had completely disappeared.

The endothelial layer of the pulmonary arteries, $\mathbb{D}$ after the second week following fulvine ad- $\overrightarrow{\mathbb{D}}$ ministration, showed some increase of endoplas- $\frac{3}{0}$ mic reticulum, which was sometimes dilated, and $\mathbb{\mathbb { Q }}$ also of mitochondria. Swelling of the endothelial $\overrightarrow{0}$ cells was regularly present, particularly from the fourth week. Eventually it led to narrowing of the lumen. It was hard to decide whether proliferation of endothelial cells contributed to this obstruction. Occasional blebs, sometimes involving the larger part of the endothelial cell body, were $\frac{0}{0}$ observed.

The normal pulmonary veins and venules, in $\overrightarrow{\overrightarrow{0}}$ contrast to the arteries, possess a single elastic lamina. In some parts of the course of the vessel the endothelial layer overlies this elastic lamina, separated only by a thin discontinuous basement $\vec{\partial}$ membrane. Elsewhere, usually over short stretches, there may be a layer of smooth muscle ${ }_{-}^{x}$ cells in the venous wall, creating intimal fibro- 3 . muscular pads. Between these muscle cells there is a fairly large amount of collagenous fibres with some scattered thin elastic fibres. The muscle cells 0 have a similar structure to those in the arteries but in addition they have plump excrescences, protruding into the overlying endothelial cells. At the sites of these excrescences a basement mem- $\tilde{N}$ brane is usually absent. The electron microscopicn structure of the venous endothelial cells is identi-N cal with that of the pulmonary arteries.

After fulvine application, several changes can be observed in the pulmonary veins. One of the most striking concerns the smooth muscle cells of $\stackrel{\Phi}{\oplus}$ the venous wall. The cytoplasmic excrescences of these cells, which were plump, short, and sparse in our control animals, became longer, more mushroom-shaped, and more numerous within $\frac{?}{\mathbb{D}}$ one week and particularly two to three weeks $\frac{\varrho}{\sigma}$ after the application of fulvine (Fig. 4). Later on, 


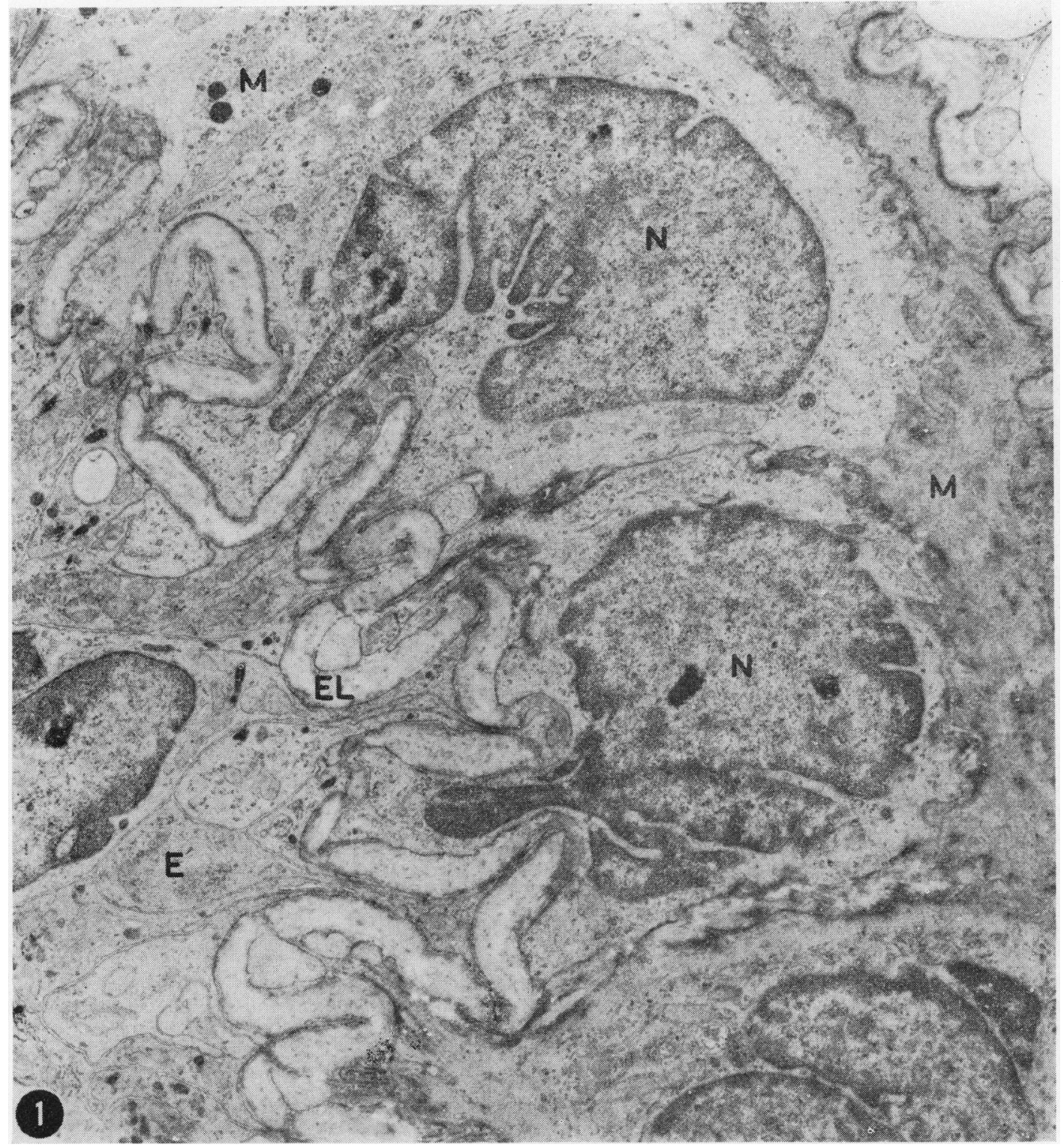

FIG. 1. Part of muscular pulmonary artery of rat two weeks after fulvine application. There is excessive crenation of the internal elastic lamina $(E L)$ with squeezing of nuclei $(N)$ of medial smooth muscle cells $(M)$. E, endothelium $(\times 12,000)$. 


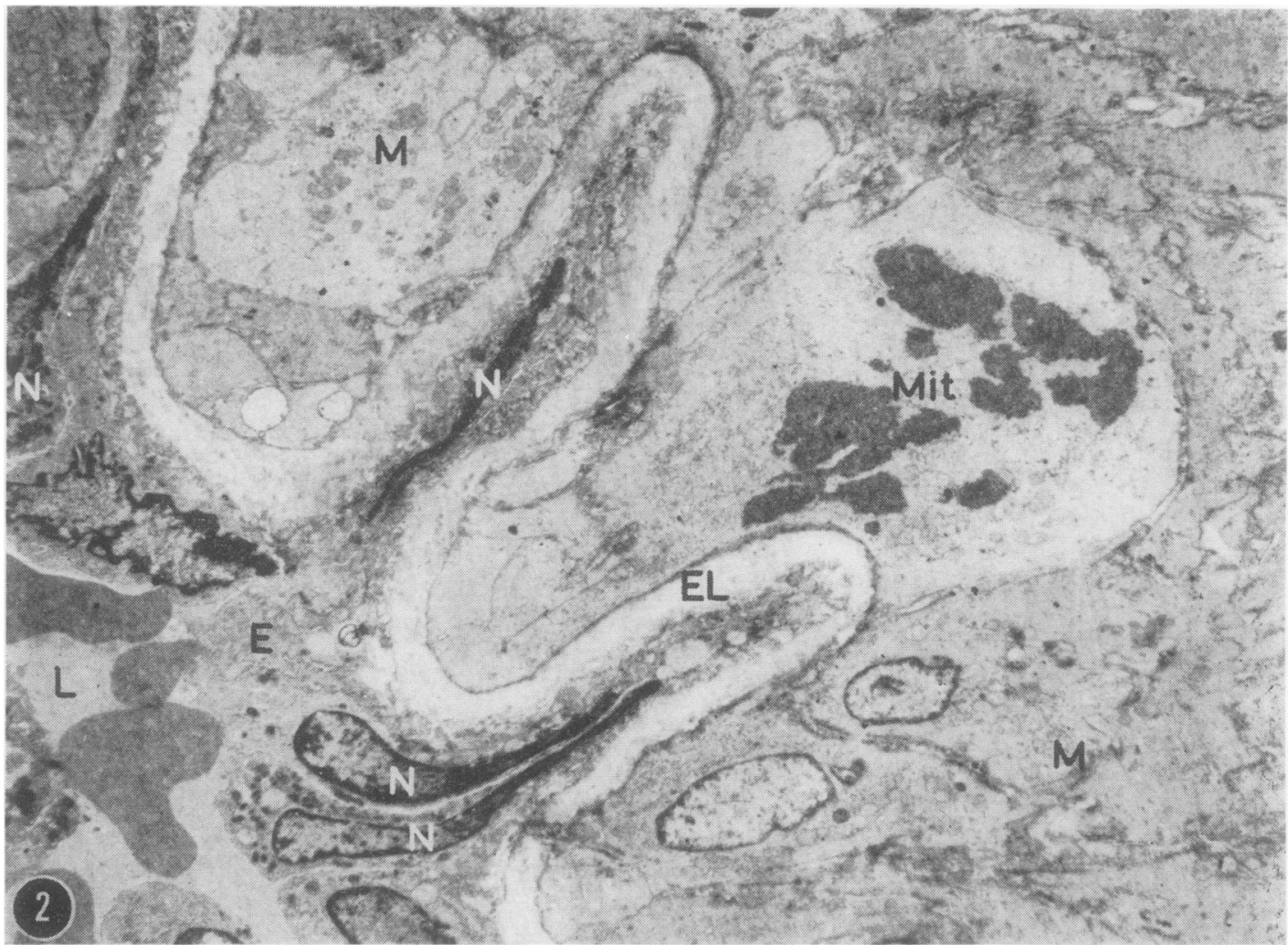

FIG. 2. Part of muscular pulmonary artery of rat four weeks after fulvine application. Nuclei $(N)$ of endothelial cells $(E)$ are squeezed between the folds of the excessively crenated internal elastic lamina $(E L)$. In the media there are smooth muscle cells $(M)$, one of which is in mitosis $(M i t) . L$, lumen $(\times 5,000)$. 


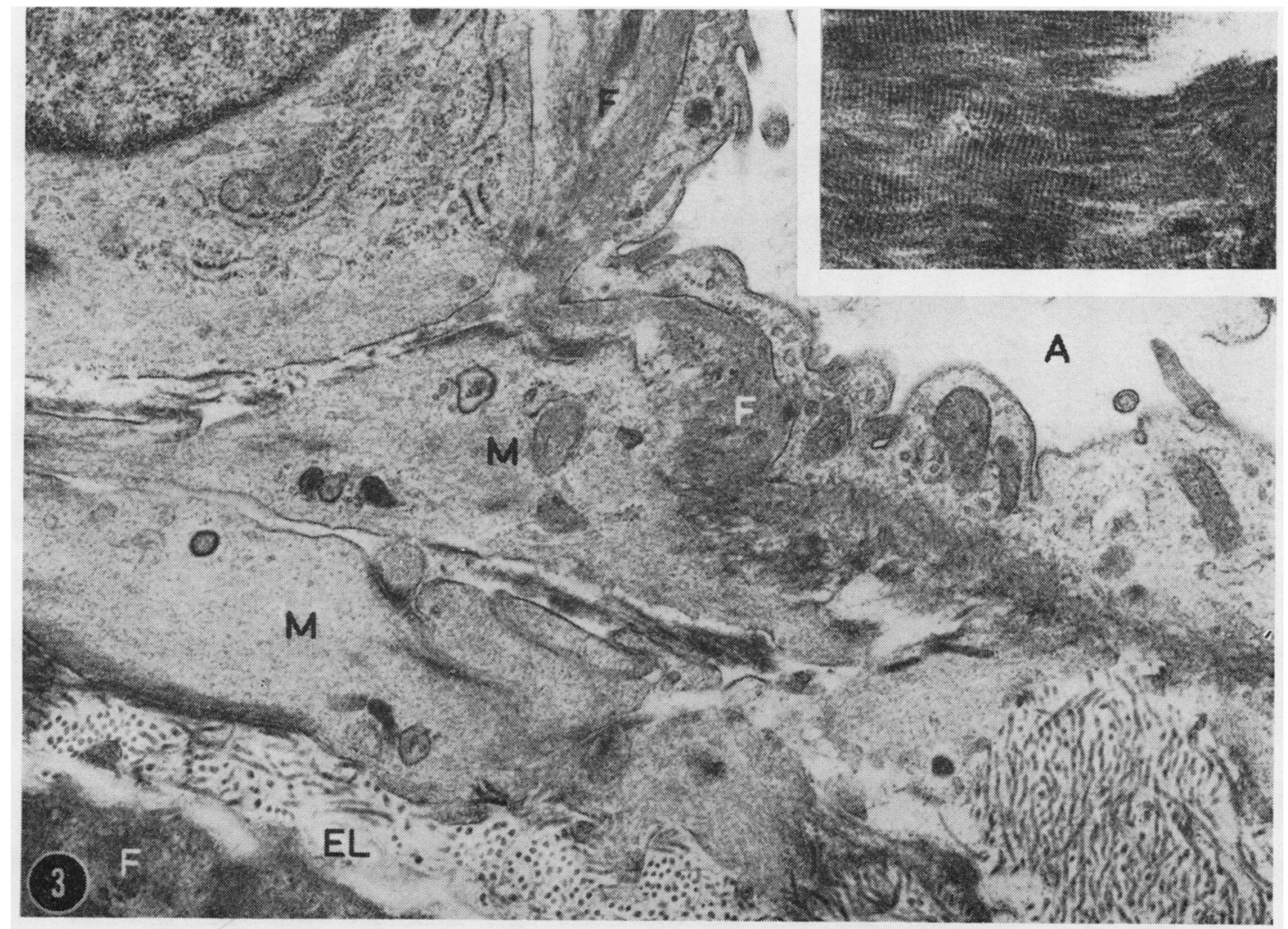

FIG. 3. Part of muscular pulmonary artery of rat four weeks after fulvine application. Smooth muscle cells (M) are lying in the adventitia outside the external elastic lamina $(E L)$. Fibrin $(F)$ is present in large amounts in the media (left lower corner) and extends into the adventitia. A, alveolar space $(\times 18,000)$. Insert: detail of fibrin deposit showing fibrillar nature and periodicity $(\times 41,600)$. 


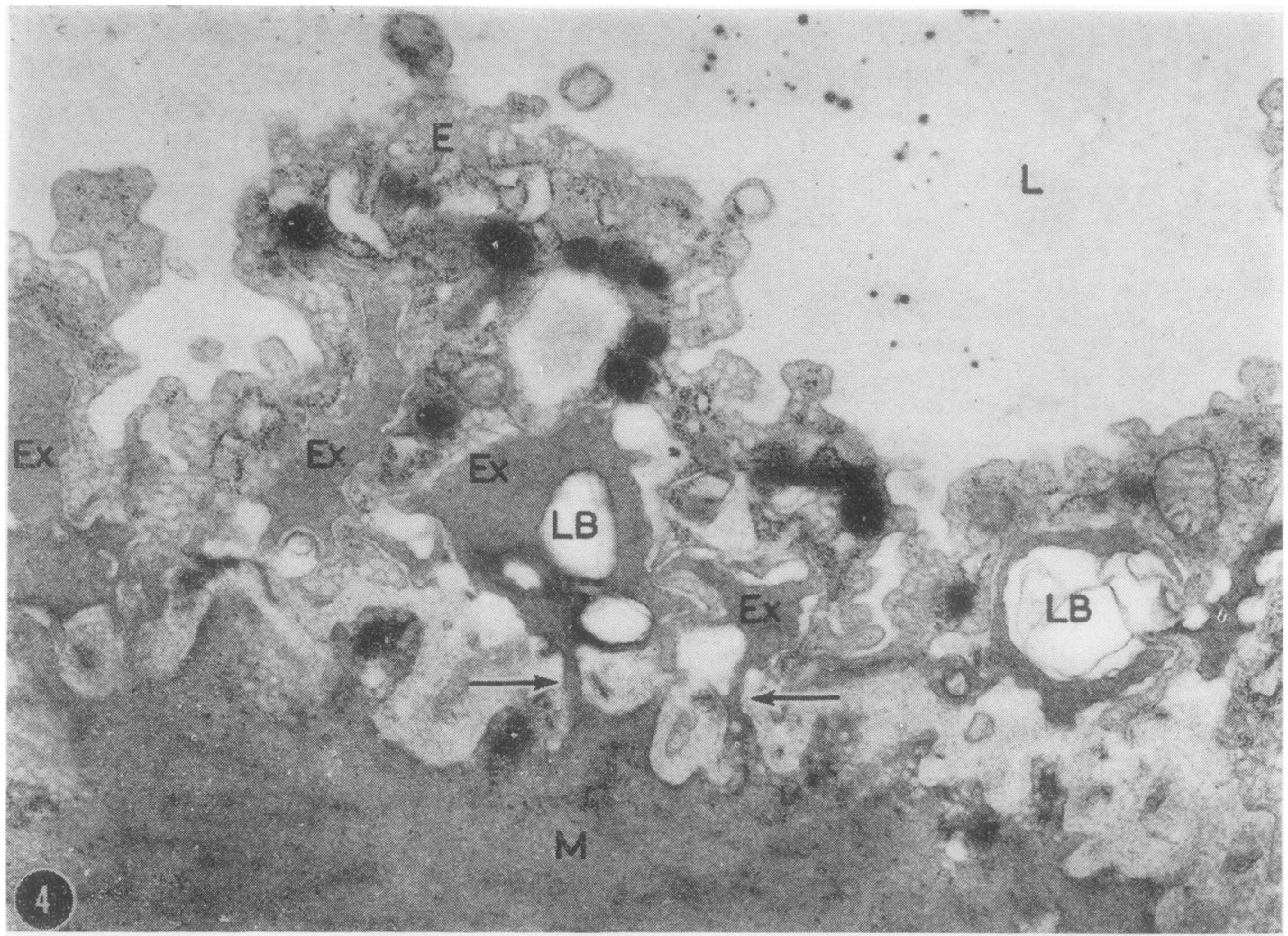

FIG. 4. Part of pulmonary vein of rat four weeks after fulvine application. Smooth muscle cells $(M)$ with cytoplasmic excrescences $(E x)$ protruding into the endothelium $(E)$. In two instances the stem connecting these excrescences with the cell body is visible (arrows). The excrescences often contain lamellar bodies $(L B)$. L, lumen $(\times 25,000)$. 
that is four weeks or more after the onset of the experiment, they were less striking and possibly less numerous. The cytoplasm of the muscle cell protruded through discontinuities of the endothelial basement membrane with a long stem forming a mass of muscular cytoplasm herniating into the endothelial cell. Often these masses of cytoplasm seemed to have no connection with the body of the muscle cell if the stem was not in the plane of section. Frequently the nucleus of the endothelial cell was wedged between two of these muscular excrescences (Fig. 5).

The cytoplasm of the muscle cells contained increasing amounts of organelles. In the cytoplasm of the excrescences there were frequent lamellar bodies (Fig. 4). Sometimes the excrescences appeared as electron-transparent blebs. Proliferation of muscle cells seemed very likely but was difficult to prove.

There was some increase of collagen and elastic fibres between the smooth muscle cells in the course of time. After four weeks deposits of fibrin became evident with gradual disintegration of the muscle cells (Fig. 6) similar to that observed in the arteries, although to a lesser extent. Even so it was sometimes difficult to distinguish veins from arteries since in both types of vessel at this stage there is only a single (external) elastic lamina.

The endothelium of the venous wall became gradually swollen, particularly after four weeks. By that time its cytoplasm contained a large amount of markedly dilated endoplasmic reticulum with evidence of degeneration. In some instances the endothelium appeared to detach itself from the media.

The swollen endothelial cells, together with contraction of smooth muscle cells, produced considerable narrowing of the vascular lumen. Even complete obliteration of these vessels occurred (Fig. 7). It is likely that proliferation of the endothelial cells played a part in this obstruction in view of the occasional mitotic activity observed with light microscopy. Clots of fibrin and particularly of platelets often added to the vascular obstruction.

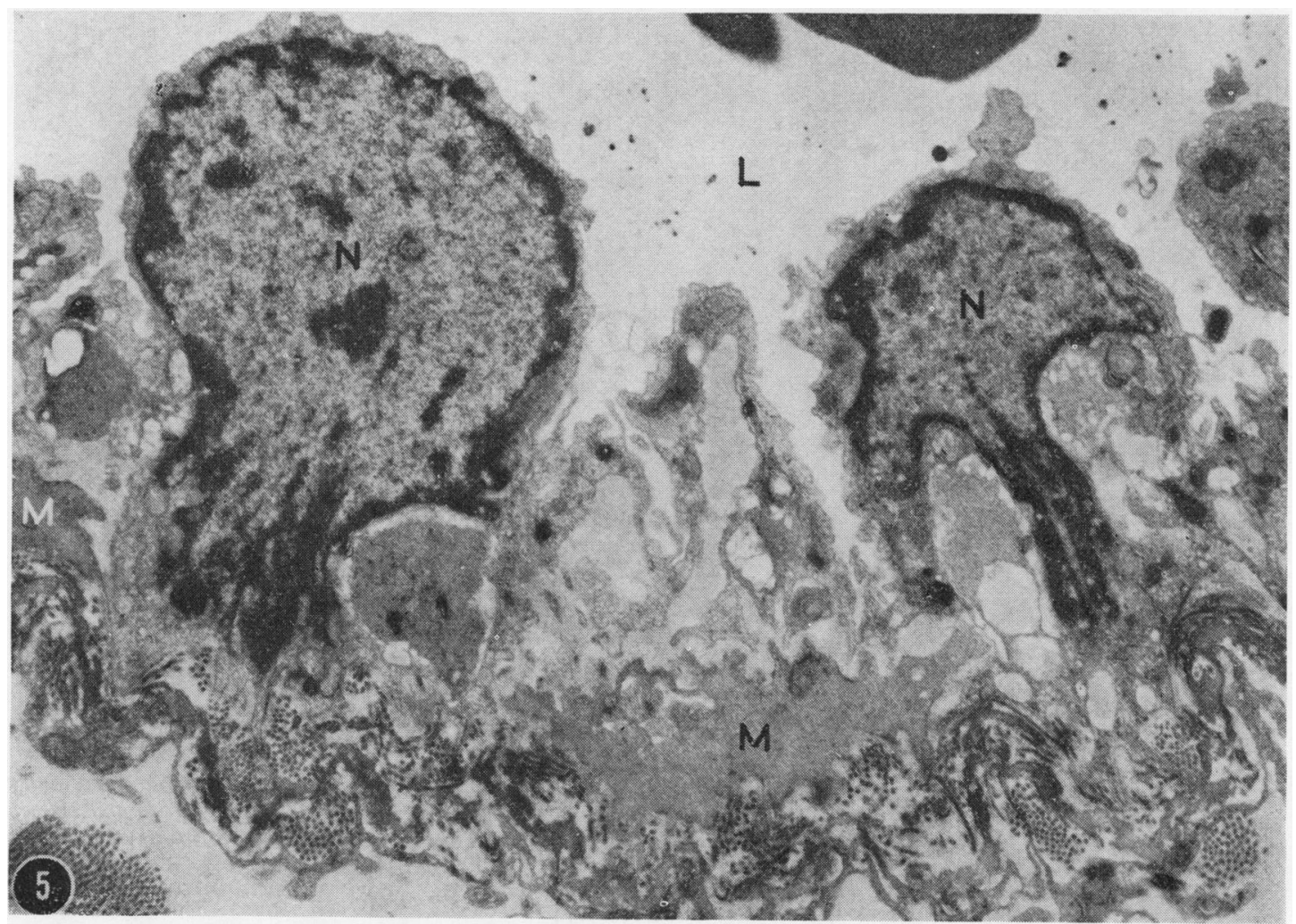

FIG. 5. Part of pulmonary vein of rat, two weeks after fulvine application. Nuclei $(N)$ of endothelial cells are wedged at their bases by cytoplasmic excrescences of smooth muscle cells $(M)$. L, lumen $(\times 8,800)$. 

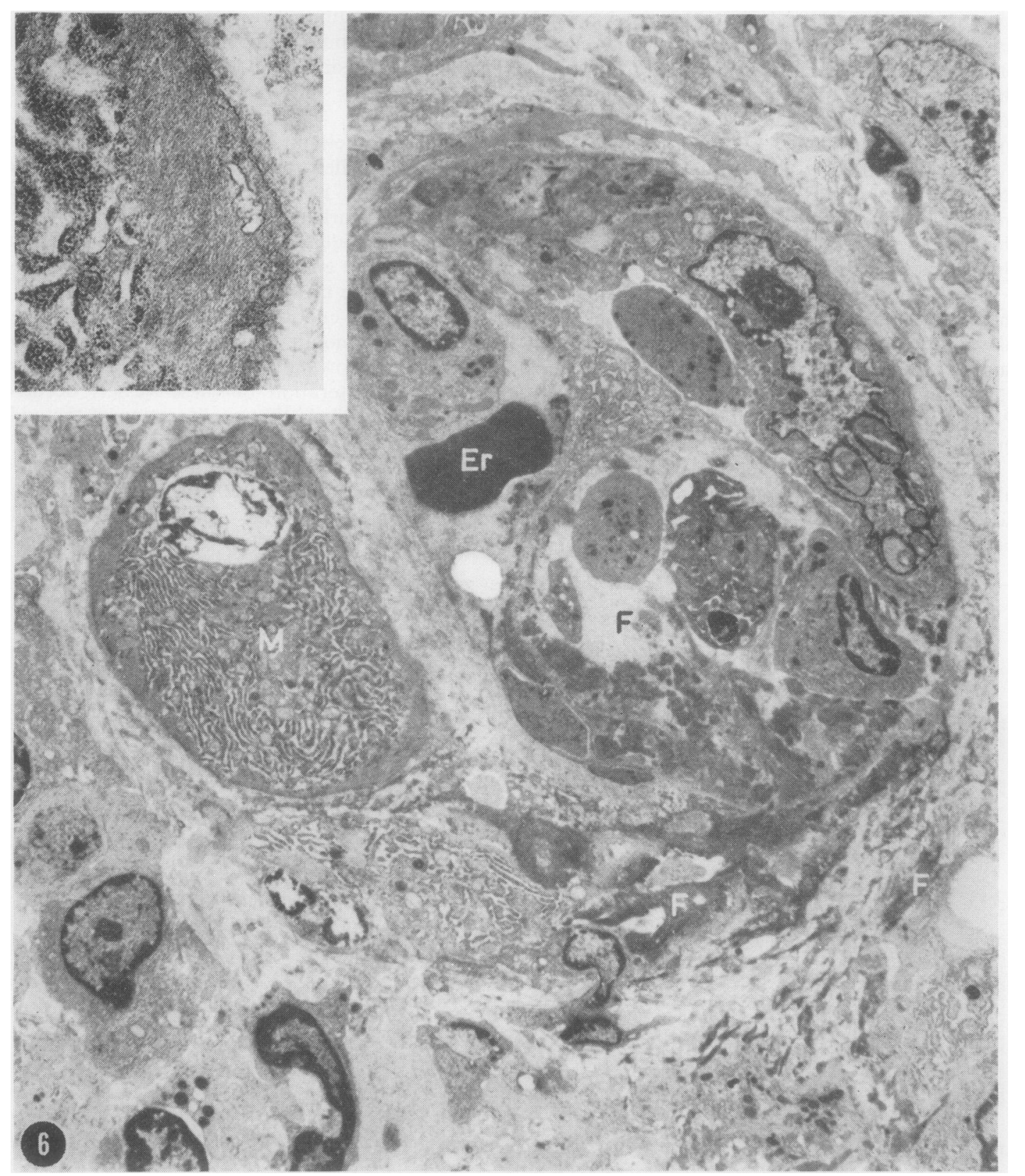

FIG. 6. Pulmonary venule of rat four weeks after fulvine application. There is a distorted and narrowed lumen containing an erythrocyte $(E r)$. Fibrin $(F)$ extends from the lumen through the wall into the adventitia. One necrotic muscle cell $(M)$, still recognizable by remnants of its fibrillar cytoplasm (insert), is characterized by marked dilatation of endoplasmic reticulum and karyolysis $(\times 5,400$; insert $\times 21,500)$. 


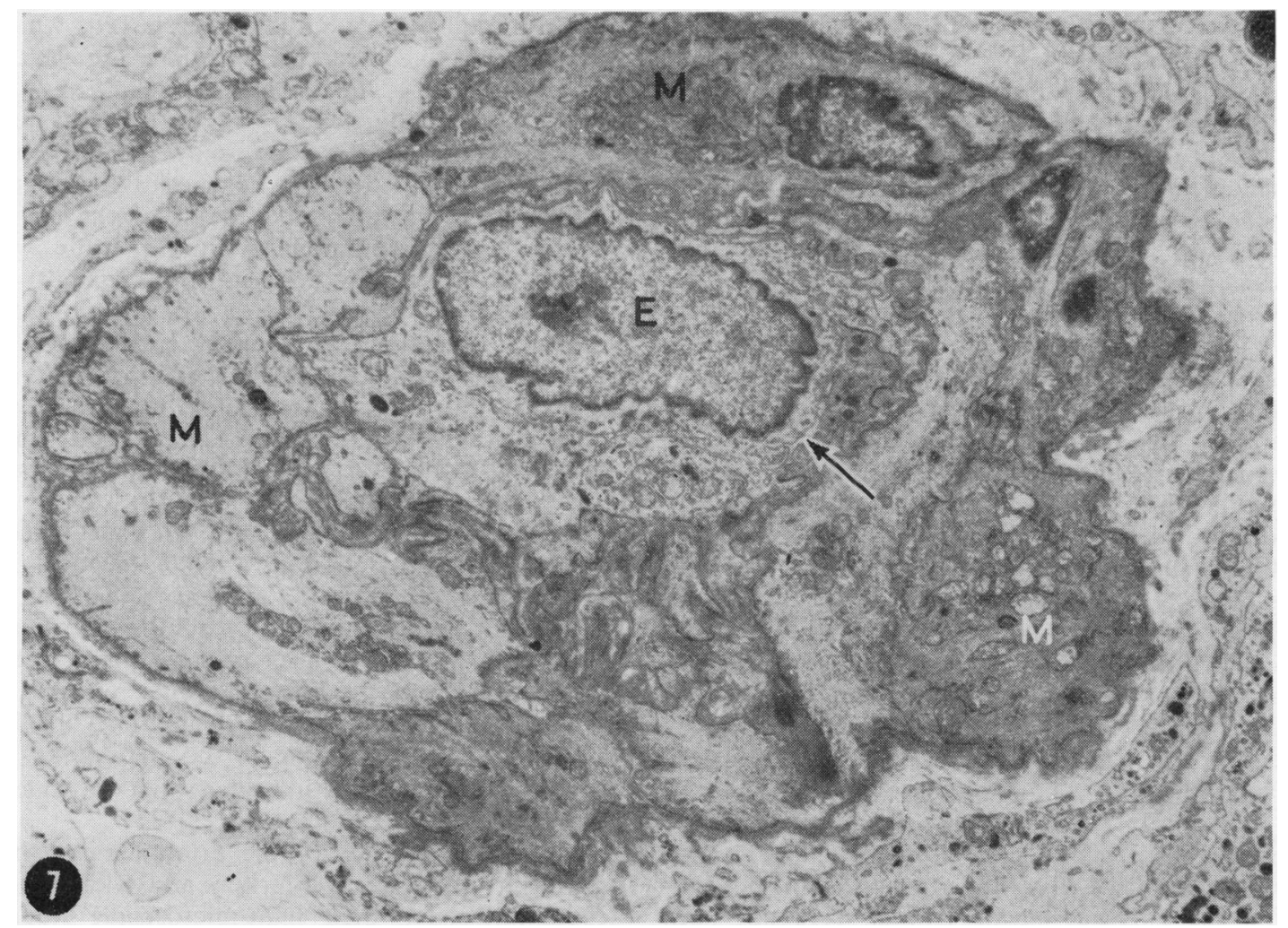

FIG. 7. Pulmonary venule of rat four weeks after fulvine application. Swelling of endothelial cells $(E)$ and contraction of muscle cells $(M)$ have led to complete occlusion of the original lumen (arrow) $(\times 5,900)$.

\section{DISCUSSION}

The effect of Crotalaria alkaloids, including fulvine, on the pulmonary circulation has received much attention. So far the various studies have been concentrated mainly on the pulmonary arteries and on the alveolar walls, and the results of these studies have been summarized by Kay and Heath (1969). Thickening of the media and fibrinoid necrosis with inflammation of the pulmonary arteries were among the most conspicuous changes.

In the preceding paper (Wagenvoort et al., 1974) constriction of the arterial media, ultimately followed by necrotizing arteritis, was demonstrated, but in addition severe vascular lesions were observed in the pulmonary veins and venules.

Electron microscopic studies on the effect of Crotalaria on the pulmonary vasculature are scarce. Kay, Smith, and Heath (1969) examined the ultrastructure of lungs in rats after digestion of Crotalaria seeds but their study was limited to alveolar walls and capillaries.

Merkow and Kleinerman (1966) studied the ultrastructural changes of the pulmonary arteries of rats after application of monocrotaline, an alkaloid closely related to fulvine and producing similar changes. Their effort was concentrated upon the late changes, particularly on fibrinoid degeneration of the arterial media.

From our material it appeared that vasoconstriction of the pulmonary arteries, as demonstrated by marked crenation of the internal elastic lamina, was an early phenomenon, always present from the second week and sometimes in the first. While the degree of crenation of this lamina is difficult to express quantitatively, the squeezing of nuclei of medial smooth muscle cells on one side, and of endothelial nuclei on the other, between the folds of the elastic membrane was never observed in control animals but regularly in the test rats. 
The nuclei of the smooth muscle cells were markedly coiled. Their cytoplasm did not reveal any characteristic changes, although there was sometimes a marked increase in organelles.

The early changes in the pulmonary arterial media, as observed with the electron microscope, correspond with our light microscopical observations of the arteries and with the early development of right ventricular hypertrophy (Wagenvoort et al., 1974).

From ultrastructural studies it is difficult to assess whether hyperplasia of smooth muscle cells takes place. The occasional mitotic figure may indicate this but mitoses are always rare in the vascular media. The development of smooth muscle fibres in the adventitia, where they are normally absent, indicates that there is an increase of vascular smooth muscle tissue, probably in response to increased pulmonary arterial pressure. This development within the adventitia has not been described before in muscular pulmonary arteries following fulvine application, although Kay, Heath, Smith, Bras, and Summerell (1971) found proliferation of smooth muscle in the adventitia of the pulmonary trunk.

It is likely that these smooth muscle cells are not derived from the media but that they develop from adventitial fibroblasts. Muscle cells penetrating the external elastic lamina have not been observed, but in the adventitia there were regularly cells with characteristics of both fibroblasts and smooth muscle cells, suggesting a transformation from one type into the other. Such a transformation would be in keeping with the close relationship existing between fibroblasts and smooth muscle cells in the walls of blood vessels (Wissler, 1967; Ross, 1972). Transition of fibroblasts to smooth muscle cells has also been described in other tissues (Nagle, Kneiser, Bulger, and Benditt, 1973).

In the walls of pulmonary veins and venules, where there is no internal elastic lamina separating the smooth muscle cells from the endothelium, the excrescences of the former cells are also likely to be due to contraction. Some excrescences, though less prominent in size and number, did occur in control rats but in these instances there was also some contraction due to collapse of the vessels. The excrescences were particularly prominent, however, both in numbers and in size, in the period from two to four weeks after fulvine application when pulmonary venous contraction was suggested by our light microscopic studies. In this respect it may be significant that Fay and Delise (1973) described evaginations of the cell membrane of isolated smooth muscle cells which were brought to contraction in response to electri cal stimulation. The frequent occurrence of lamellar bodies, particularly in the excrescenceso of the smooth muscle cells, may indicate that ${ }^{\rho}$ these were the sites of early degenerative changes. $\vec{\circ}$

An increase of both smooth muscle cells and of collagen in the pulmonary venous walls was suggestive from our material but difficult to quantitate.

Simultaneous contraction and hyperplasia of pulmonary arterial and venous media points to an angiotoxic effect from fulvine or its derivatives on both types of vessel at the same time, rathero than a pulmonary arterial reaction to increased pulmonary venous pressure.

In the later stages, that is from the fourth weeko after the administration of fulvine, deposits of fibrin were observed in the arterial media, first aso fairly small streaks in the intercellular spaces and possibly in the cytoplasm of smooth muscle cells. $\vec{y}$ Later, practically the whole media was of ten changed in an electron-dense mass. The fibrillaro nature of this material and the periodicity of approximately $180 \AA$ indicated that it indee ${ }^{\circ}$ consisted of fibrin.

Fibrinoid vasculosis of the arterial media has also been described by Merkow and Kleinerman (1966). Although their light-microscopic studies suggested to them that there was actual necrosis of the media, they could not find ultrastructura $\vec{E}$ evidence to this effect. On the contrary, the found an increased number of cytoplasmic organ elles, suggesting increased activity of the smooth muscle cells.

We have also found some increase of cytoplas mic activity but, particularly in the later stages there was, in addition to fibrin deposition, dis tinct disintegration of the muscle cells with loss of fibrillar structure. Partly necrotic, but still recog nizable muscle cells were even shed into the lumers. of the vessel. Apparently the earlier stages of fibrin deposition are accompanied by increased activity of the muscle cells but eventually dis 0 tinct fibrinoid necrosis supervenes.

Fibrin deposits and disintegration of smootho muscle occurred equally, though less frequentlyo in pulmonary veins and venules. To our know ledge this has not been described before.

Fibrinoid vasculosis and necrosis are featureso not uncommonly seen in cases of vasoconstrictive pulmonary hypertension, such as in congenita cardiac defects or primary pulmonary hyperten $\stackrel{\oplus}{\propto}$ sion (Wagenvoort, Heath, and Edwards, 1964) It is believed that it results from spastic contracs 
tion of the vascular media in these cases (Wagenvoort, 1973). In view of the severe vasoconstrictive effect of fulvine application, a similar sequence of changes may be present here. But that the disintegration of the muscle cells is a direct effect of fulvine or its derivatives cannot be disproved.

It is likely that fibrin enters the vascular wall as a result of increased permeability, as suggested by Merkow and Kleinerman (1966). Degenerative changes of the endothelial layer, clearly demonstrable in our material, are probably basic to this mechanism.

\section{REFERENCES}

Fay, F. S. and Delise, C. M. (1973). Contraction of isolated smooth-muscle cells; Structural changes. Proceedings of the National Academy of Sciences, 70, 641 .

Kay, J. M. and Heath, D. (1969). Crotalaria spectabilis. The Pulmonary Hypertension Plant. Thomas, Springfield, Illinois.

- - Smith, P., Bras, G., and Summerell, J. (1971). Fulvine and the pulmonary circulation. Thorax, 26, 249.

, Smith, P., and Heath, D. (1969). Electron microscopy of Crotalaria pulmonary hypertension. Thorax, 24, 511.
Merkow, L. and Kleinerman, J. (1966). An electron microscopic study of pulmonary vasculitis induced by monocrotaline. Laboratory Investigation, 16, 547.

Nagle, R. B., Kneiser, M. R., Bulger, R. E., and Benditt, E. P. (1973). Induction of smooth muscle characteristics in renal interstitial fibroblasts during obstructive nephropathy. Laboratory Investigation, 29, 422.

Ross, R. (1972). The arterial smooth muscle cell. In: Pathogenesis of Atherosclerosis, edited by R. W. Wissler and J. C. Geer. Williams and Wilkins Company, Baltimore.

Wagenvoort, C. A. (1973). Hypertensive pulmonary vascular disease complicating congenital heart disease: a review. Cardiovascular Clinics, 5, 43.

Heath, D., and Edwards, J. E. (1964). The Pathology of the Pulmonary Vasculature. Thomas, Springfield, Illinois.

—, Wagenvoort, N. and Dijk, H. J. (1974). Effect of fulvine on pulmonary arteries and veins of the rat. Thorax, 29, 522.

Wissler, R. W. (1967). Editorial. The arterial medial cell, smooth muscle, or multifunctional mesenchyme? Circulation, 36, 1.

Requests for reprints to: Professor C. A. Wagenvoort, Department of Pathological Anatomy, Wilhelmina Gasthuis, University of Amsterdam, The Netherlands. 